\title{
EVALUATION CRITERIA OF THE BELT CONVEYOR USING THE AHP METHOD AND SELECTION OF THE RIGHT CONVEYOR BY HURWITZ METHOD
}

\author{
Stefan Jovčićc', Petr Průša', Svetlana Nikolicic² \\ 1 University of Pardubice, The Faculty of Transport Engineering, Studentská 95, 53210 Pardubice, Czech \\ Republic, e-mail: stefan.jovcic93@gmail.com, petr.prusa@upce.cz \\ 2 Faculty of Technical Sciences, University of Novi Sad, Dr Zorana Đinđića 1, 21101 Novi Sad, Republic of Serbia, \\ e-mail: cecan@uns.ac.rs
}

Received: 2017.04.04

Accepted: 2018.05.04

Published: 2018.06.01

\begin{abstract}
The subject of the research paper is evaluation of different criteria that ought to be taken into consideration while deciding about conveyor type. Analythical Hierarchy Process (AHP) is a well known multicriteria analysis method in evaluation of criteria. Five experts in the field of conveyor transport have been consulted and according to that evaluation was performed. After that, Hurwitz method was used on the particular case including some of the subcriterias of evaluated criteria by the experts and the best solution of the belt conveyor has been selected.
\end{abstract}

Keywords: AHP method, Conveyor, multi-criteria analysis, Hurwitz method.

\section{INTRODUCTION}

Transport by conveyors is of big importance for logistics industry. Conveyor transport process includes various types of carriage of goods through various and specific technological processes. Burdzik et al. [1] emphasized that was extremely important that the implementation of the transport process was strictly matched with a specific technology.

Conveyors are the units of transport in logistical plants that connect individual logistical production process [2]. Švadlenka et al. [3] exposed that current logistics and individual process, eighter in manufacture or in processing and distribution of material and goods are characterized by continual increase of demands as well as by change of the demanded, related volume of performance. That change means not only increase in transport of goods and materials, but also the change of dynamic and qualitative parameters of processing and distribution process such as speed, time, accuracy and reliability.

Conveyors are most often used for the purposes of logistic centers for transport of different types of goods in different combinations [4]. Logistic services cannot be imagined without support of conveyors. Kampf et al. [5] emphasized that logistic center is a point designed for concentration of a wide variety of logistic services, including combined transportation (conveyor, forklifts, trucks) and there should be a possibilities to organise services through at least two transport modes (road, railway, water).

One of the most important system of mechanical handling equipment that moves material from one location to another in production plants is the conveyor system. Nowadays, there are a lot of different types of conveyor systems, such as: chain conveyor, that are the most often used in automotive industries, roller conveyor, which mostly conveys boxed produce at the distribution center, pneumatic, vertical, gravity conveyor, belt conveyor etc.

In this paper, the emphasis is placed on the assessment of the criteria when choosing the belt conveyor. The belt can be made of a variety of materials with a variety of surfaces, depending on the items it is intended to convey [6]. In fact, 


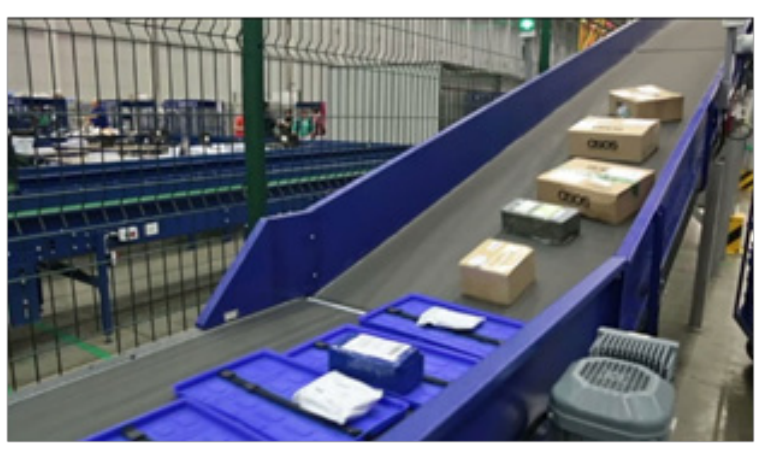

Fig. 1. Moving boxes by belt conveyor [7]

belt conveyors are used in material handling, such as those moving parcels (or boxes) along inside a plant and bulk material handling such as those used in transporting material such as grain, sand, stones, ore, etc. (Figure 1).

For selection of appropriate technique such as conveyor we can use several different criterias. It could be economical, ecological, external costs, technical etc. [8]. By consulting several experts from the filed of conveyor transport, the authors of this paper decided to use three of criteria for evaluation of appropriate conveyor. Those of three criteria are technological, economical and external costs. Each of these criteria has subcriterias and it can be seen in the rest of this paper.

In recent years there has been a strong development and unusual popularity of multi-criteria analysis method. In practical terms, the methods of multi-criteria analysis provide great assistance in solving every day tasks, decision-making and management actions. When making decisions about achieving the goal, the company usually has several alternatives that compares to the criteria and finally, with the help of some of the methods of multi-criteria analysis comes to the conclusion about the best possible solution. The Analytic Hierarchy Process (AHP) was proposed by professor Saaty in 1970s. Gaudenzi and Borghesi [9] used AHP method for managing risks in the supply chain. Saaty [10] used this method for decision making for leaders. Also, this method can be used when buying a car, selecting equipment for manipulating production processes, making investment decisions etc. The authors decided to use this method, because it was shown as very useful in practical work. It is widely used in decision making in modern business. It presents a practical tool for support of decision making, systematic method for comparing and evaluating a list of objectives or alternatives.

Hurwitz method is also a good method for evaluation of a set of alternatives. The idea of this method is to take into account the pessimistic and optimistic approach to the problem. When we find a values of alternatives, by ranking them from the biggist to the smallest value, we can chose the best one. It will be presented later in this paper.

The rest of the paper is organized as follows: the second section is AHP methodology, third section describes the evaluation of particular problem. Fourth section prove consistency checking for evaluated problem. Hurwitz method with particular case of belt conveyor selection is given in section five. Sector 6 concludes this paper.

\section{ANALYTIC HIERARCHY PROCESS METODOLOGY}

AHP method presents a practical tool for support of decision making, systematic method for comparing a list of objectives or alternatives. Warfield [11] emphasized that in basically, AHP is a structural modeling methodology that, in addition to qualitative structuring, incorporates numbers

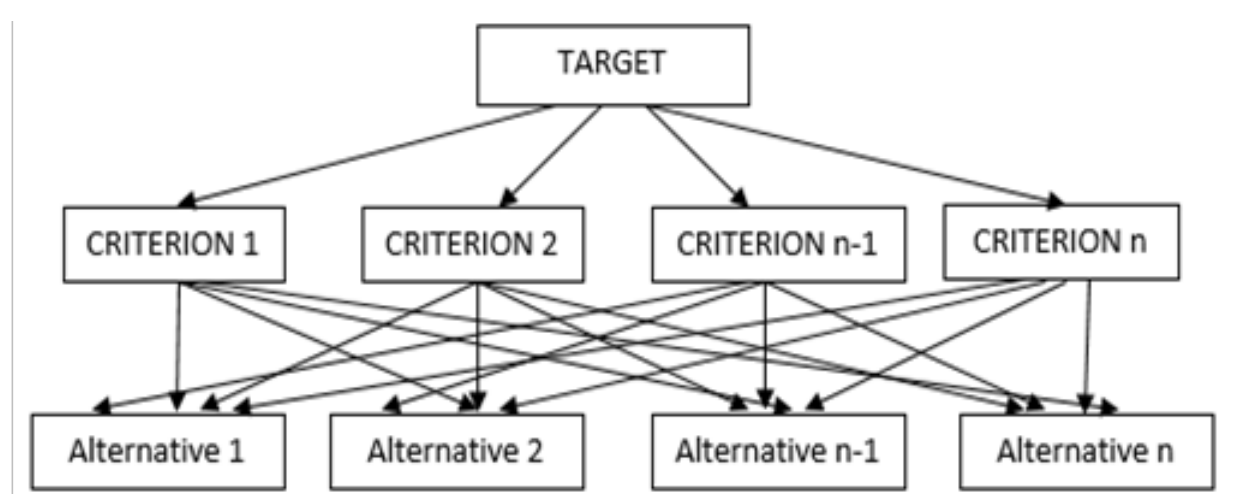

Fig. 2. General hierarchy structure of AHP 
Table 1. Comparison matrix

\begin{tabular}{|c|c|c|c|c|}
\hline Criterias & $\mathrm{C}_{1}$ & $\mathrm{C}_{2}$ & $\ldots$ & $\mathrm{Cn}_{\mathbf{n}}$ \\
\hline $\mathrm{C}_{1}$ & $\mathrm{C}_{11}$ & $\mathrm{C}_{12}$ & $\ldots$ & $\mathrm{C}_{1 \mathrm{n}}$ \\
\hline $\mathrm{C}_{2}$ & $\mathrm{C}_{21}$ & $\mathrm{C}_{22}$ & $\ldots$ & $\mathrm{C}_{2 \mathrm{n}}$ \\
\hline$\ldots$ & $\ldots$ & $\ldots$ & $\ldots$ & $\ldots$ \\
\hline $\mathrm{C}_{\mathrm{n}}$ & $\mathrm{C}_{\mathrm{n} 1}$ & $\mathrm{C}_{\mathrm{n} 2}$ & $\ldots$ & $\mathrm{C}_{\mathrm{nn}}$ \\
\hline
\end{tabular}

$\mathrm{C}_{1} \ldots \mathrm{C}_{\mathrm{n}}-$ number of alternatives

$\mathrm{c}_{11} \ldots \mathrm{c}_{\mathrm{nn}}-$ evaluations of alternatives according to Saaty's scale

on the arcs of the structure in the form of weights. AHP is specifically designed to be used by practitioners themselves, although technical help may be required for large and complex problems. Furthermore, AHP can be used with many types of data, including judgments based on experience and values as well as objective data. The problem can be represented schematically (Figure 2).

In solving a decision problem, it is usually presented in form of comparison matrix, Table 1.

In works $[12,13,14]$ the axioms is defined on which AHP is based:

- Axiom of reciprocity. If element A $\mathrm{n}$ times is more significant than element $\mathrm{B}$, then element B $1 / n$ times is more significant than element $A$.

Table 2. Saaty's scale for evaluating alternatives

\begin{tabular}{|c|c|c|}
\hline Note & Definition & Explanation \\
\hline 1 & The same meaning & $\begin{array}{l}\text { Two elements are identical } \\
\text { in meaning to target }\end{array}$ \\
\hline 3 & Poor Dominance & $\begin{array}{l}\text { Experience or judgment } \\
\text { slightly favors one element } \\
\text { in relation to the other }\end{array}$ \\
\hline 5 & Strong dominance & $\begin{array}{l}\text { Experience or judgment } \\
\text { considerably favor one ele- } \\
\text { ment in relation to the other }\end{array}$ \\
\hline 7 & $\begin{array}{l}\text { Demonstrated } \\
\text { dominance }\end{array}$ & $\begin{array}{l}\text { The dominance of one ele- } \\
\text { ment confirmed in practice }\end{array}$ \\
\hline 9 & Absolute dominance & $\begin{array}{l}\text { Highest degree of domi- } \\
\text { nance }\end{array}$ \\
\hline $\begin{array}{l}2,4 \\
6,8\end{array}$ & Among the values & $\begin{array}{l}\text { Compromise needed or } \\
\text { further division }\end{array}$ \\
\hline
\end{tabular}

Table 3. Example of using Saaty's scale

\begin{tabular}{|c|c|c|c|}
\hline Criterias & C1 & C2 & C3 \\
\hline C1 & 1 & 5 & $1 / 3$ \\
\hline C2 & $1 / 5$ & 1 & 2 \\
\hline C3 & 3 & $1 / 2$ & 1 \\
\hline
\end{tabular}

- The axiom of homogeneity. The comparison makes sense only if the elements are comparable, for example, we can not compare the weight of an ant and the weight of an elephant.

- Axiom of dependence. A comparison is made between a group of elements of one level in relation to the higher level element, i.e. Comparisons at a lower level depend on the higher-level element.

- Expectation axiom. Any change in the structure of the hierarchy requires re-calculation of priorities in the new hierarchy.

For example, if we have 3 criteria, the relationships between them can be described in the table bellow.

After evaluating criterias, the next step is normalisation of the data. It means for data to be between intervals 0 and 1 . After normalising the data, it is necessary to compute the sum of each column and then divide each column by the corresponding sum. From the obrained values it is neccesary to find average values by each rows and it represent the weights of criteria. This weights would be used in summing the measures as required in the evaluation of the objective hierarchy. For this example, the weights would be as indicated in Table 4.

\section{THE EVALUATION PROBLEM}

When making a decision about selection of conveyors, there are some of the criterias which are of big importance to that special attention must be payed. It's necessary to evaluate which is the most important criteria for selection of belt

Table 4. Normalisation and determination of the weights

\begin{tabular}{|c|c|c|c|c|c|c|c|c|}
\hline Criterias & C1 & C2 & C3 & Criterias & C1 & C2 & C3 & Weights \\
\hline C1 & 1 & 5 & $1 / 3$ & C1 & 0.181 & 0.769 & 0.100 & 0.345 \\
\hline C2 & $1 / 5$ & 1 & 2 & C2 & 0.036 & 0.153 & 0.600 & 0.262 \\
\hline C3 & 3 & $1 / 2$ & 1 & C3 & 0.857 & 0.076 & 0.300 & 0.411 \\
\hline$\Sigma$ & 5.50 & 6.50 & 3.33 & \multicolumn{7}{|c}{} \\
\hline
\end{tabular}


Table 5. Evaluation of experts

\begin{tabular}{|c|c|c|c|c|c|}
\hline $\begin{array}{c}\text { Expert/ } \\
\text { criteria }\end{array}$ & $\begin{array}{c}\text { Expert } \\
\mathbf{1}\end{array}$ & $\begin{array}{c}\text { Expert } \\
\mathbf{2}\end{array}$ & $\begin{array}{c}\text { Expert } \\
\mathbf{3}\end{array}$ & $\begin{array}{c}\text { Expert } \\
\mathbf{4}\end{array}$ & $\begin{array}{c}\text { Expert } \\
\mathbf{5}\end{array}$ \\
\hline $\mathrm{C} 1: \mathrm{C} 2$ & 3 & 2 & 3 & 3 & 5 \\
\hline $\mathrm{C} 1: \mathrm{C} 3$ & 0.33 & 4 & 0.33 & 0.20 & 2 \\
\hline $\mathrm{C} 2: \mathrm{C} 3$ & 0.20 & 0.33 & 0.33 & 2 & 0.33 \\
\hline
\end{tabular}

Table 6. The comparison matrix

\begin{tabular}{|c|c|c|c|}
\hline Criterias & C1 & C2 & C3 \\
\hline C1 & 1 & 3 & 3 \\
\hline C2 & 0.33 & 1 & 2 \\
\hline C3 & 0.33 & 0.50 & 1 \\
\hline$\Sigma$ & 1.67 & 4.50 & 6 \\
\hline
\end{tabular}

Table 7. Normalization of input data

\begin{tabular}{|c|c|c|c|}
\hline Criterias & C1 & C2 & C3 \\
\hline C1 & 0.60 & 0.67 & 0.50 \\
\hline C2 & 0.20 & 0.22 & 0.33 \\
\hline C3 & 0.20 & 0.11 & 0.17 \\
\hline
\end{tabular}

Table 8. The criteria weights

\begin{tabular}{|c|c|}
\hline Criteria & Weight \\
\hline C1 & 0.59 \\
\hline C2 & 0.25 \\
\hline C3 & 0.16 \\
\hline
\end{tabular}

conveyor. Three criteria have been taken into consideration:

$\mathrm{C} 1$ - Economical criteria - this criteria is including price of conveyor, maintenance costs and energy costs during the one year of usage

$\mathrm{C} 2$ - Technological criteria - this criteria is represented by the speed of the conveyor belt and shipping quantity

C3 - External costs - representing evaluation of external costs such as noise and polution

As noted above, in the assessment of the criteria, five experts in the field of conveyor transport have been consulted. Their estimates are presented in the Table 5.

Based on the estimates by the experts, the authors agreement took into account the geometric mean score of all the experts for each pair of compared criteria and on this basis, the following Table 6 of input data was filled.

The next step of evaluation is normalization of the data from comparison matrix, that is, reduce the data between interval from 0 to 1 . The next Table 7 presents normalization.

By finding the average values by rows in a given normalized matrix, the weights (the importance of one criteria related to another) of given criteria is determined. This is shown in the Table 8 .

According to calculation, the biggest importance is given to economical criteria (59\%), then technological criteria (25\%) and on the end is external costs with the smallest value (16\%). To be sure about this evaluation, the authors have resorted to consistency checks.

\section{CHECKING CONSISTENCY}

However, in order for this assessment to be considered regular, what is necessary is to carry out a consistency check, since man is in many cases inconsistent in evaluating qualitative elements. If it can be showed that the matrix of the assessment of the experts is consistent, which leads to greater reliability in making decisions, the solution for the choice of the alternative can be accepted as it is attached above.

If there was a possibility to precisely determine the values of the weight coefficients between all the elements that are compared to a given level of hierarchy, the own values of the matrix would be completely consistent. However, to the extent that it is claimed that the criterias are not the same with each other, then there is inconsistency, and the reliability of the accuracy of the results decreases. The degree of consistency is calculated on the basis of the consistency index. Indication of the level of consistency in the literature usually indicates the $\mathrm{CR}$, while the consistency index $\mathrm{CI}$ benefits. The consistency index is calculated on the basis of the following formula:

$$
\mathrm{CI}=\lambda \max -1 / \mathrm{n}-1
$$

Where is $\lambda \max$ the own value of the matrix of comparison, and which is closer to the number of criterias, this will be a minor inconsistency. In order to obtain $\lambda \max$ it is necessary to multiply the initial matrix of the comparison with the vector of the weight coefficients and in this way the vector „p“ is determined. By dividing the vector „p“ with the weights coefficients (W1, W2 ... Wn) we obtain the matrix of $\lambda(\lambda 1, \lambda 2, \ldots \lambda n) . \lambda \max$ is obtained from the formula (2): 
Table 9. Satty's (1980) scale of random index (RI) [7]

\begin{tabular}{|c|c|c|c|c|c|c|c|c|c|c|c|c|c|c|c|}
\hline $\mathbf{n}$ & $\mathbf{1}$ & $\mathbf{2}$ & $\mathbf{3}$ & $\mathbf{4}$ & $\mathbf{5}$ & $\mathbf{6}$ & $\mathbf{7}$ & $\mathbf{8}$ & $\mathbf{9}$ & $\mathbf{1 0}$ & $\mathbf{1 1}$ & $\mathbf{1 2}$ & $\mathbf{1 3}$ & $\mathbf{1 4}$ & $\mathbf{1 5}$ \\
\hline $\mathrm{RI}$ & 0.0 & 0.0 & 0.58 & 0.9 & 1.12 & 1.24 & 1.32 & 1.41 & 1.45 & 1.49 & 1.51 & 1.48 & 1.56 & 1.57 & 1.59 \\
\hline
\end{tabular}

$$
\lambda \max =1 / n \sum_{n=1}^{n} \lambda i
$$

Since in our problem, $n=3, \lambda \max$ is obtained from the formula (1), the consistency index CI is obtained. Saaty [15] also defined a table of generated random indexes, depending on the choice of the number of criterias. This is shown in Table 9.

If the degree of consistency (CR) is less than 0.10 , the result is sufficiently accurate and there is no need for corrections in comparisons and repetition of the budget. If the degree of consistency is greater than 0.10 , the results should be re-analyzed and the reasons for inconsistency determined, removed by partial repetition in pairs, and if repeating the procedure in several steps does not reduce the degree of consistency to a tolerant limit of 0.10 , all the results should be discarded and the whole procedure should be repeated from the beginning.

Finally, in our case when we use previous formulas, it can be obtained for $\lambda \max =3.0539$, $\mathrm{CI}=0.0269$ and because we have three criteria, random index will be $\mathrm{RI}=0.58$. In this case, degree of consistency $(\mathrm{CR})$ will be $\mathrm{CR}=0.0464$ and it is less than 0.1. It can be concluded that assessment has done correct.

\section{BELT CONVEYOR SELECTION BY HURWITZ METHOD}

According to Molnár et al. [16] the belt conveyor is a commonly used equipment of continuous transport. It has a high efficiency and large conveying capacity, simpler construction, small amount of maintenance.

Taking into consideration importance when choosing the belt conveyors, authors decided to combine technical and economical criteria and comparing them in order to come to the conclusion which of the belt conveyor to chose. The decision means to choose one option from a list of potentially viable variants against several criteria in a given situation, emphasized Stopka and Kampf [17]. Hurwitz method is based on the formula (3):

$\mathrm{A}^{*}=\left[\mathrm{A}_{\mathrm{i}} \mid \max _{i}\left[\alpha \min _{j} r i j+(1-\alpha) \max _{j} r i j\right]\right](3)$ where is: $\mathrm{A}^{*}$ - the best alternative and $\alpha$ - coefficient of pessimism-optimism

In our example, by the authors agreement it was accepted that the coefficient of pessimism-optimism is $0.5(\alpha=0.5)$. If $\alpha=0$ then it is negative, otherwise is positive $\alpha=1$. The following characteristics for all conveyors are given in the Table 10.

Interestingly, the speed of the belt is on the highest level, so, the first criteria will be max type. The electricity power of the conveyor is also on the highest level, shipping quantity as well. As far as the price is concerened, it is normal that we want to pay as less as possible so, cost of $1 \mathrm{~m}$ of the belt have to be min type.

Another step is normalization of the input data. Normalization is done by the following formula, depending on the type of criteria (max or min type). The following Table 11 is given bellow.

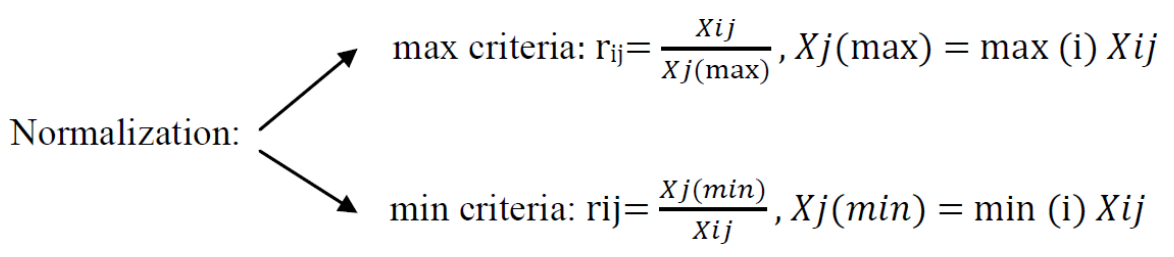

Table 10. Criterias of belt conveyors

\begin{tabular}{|c|c|c|c|c|}
\hline Conveyor/Criterias & Speed of the belt [m/s] & Electricity power [KW] & Shipping quantity [t/h] & $\begin{array}{c}\text { Cost of 1m of the belt } \\
\text { [Euro] }\end{array}$ \\
\hline Conveyor 1 & 2.4 & 50 & 140 & 250 \\
\hline Conveyor 2 & 1.5 & 30 & 300 & 350 \\
\hline Conveyor 3 & 1.25 & 15 & 100 & 270 \\
\cline { 2 - 5 } & $\max$ & $\max$ & $\max$ & $\min$ \\
\hline
\end{tabular}


Table 11. Normalization of the input data

\begin{tabular}{|c|c|c|c|c|c|c|}
\hline $\begin{array}{c}\text { Criterias/ } \\
\text { Conveyor }\end{array}$ & $\begin{array}{c}\text { Speed of the } \\
\text { belt }[\mathbf{m} / \mathbf{s}]\end{array}$ & $\begin{array}{c}\text { Electricity } \\
\text { power [kW] }\end{array}$ & $\begin{array}{c}\text { Shipping } \\
\text { quantity [t/h] }\end{array}$ & $\begin{array}{c}\text { Cost of } 1 \mathrm{~m} \text { of } \\
\text { the belt [Euro] }\end{array}$ & $\begin{array}{c}\min \text { rij } \\
\mathbf{j}\end{array}$ & $\begin{array}{c}\max \text { rij } \\
\mathbf{j}\end{array}$ \\
\hline Conveyor 1 & 1 & 1 & 0.466 & 1 & 0.466 & 1 \\
\hline Conveyor 2 & 0.625 & 0.60 & 1 & 0.714 & 0.60 & 1 \\
\hline Conveyor 3 & 0.520 & 0.30 & 0.33 & 0.925 & 0.30 & 0.925 \\
\hline
\end{tabular}

If we use the previous Hurwitz formula, we have the following results:

Conveyor $1=0.5 * 0.466+0.5 * 1=0.733$

Conveyor $2=0.5 * 0,60+0.5 * 1=0.80$

Conveyor $3=0.5 * 0.30+0.5 * 0.925=0.621$

The highest value is conveyor 2 with 0.80 , than conveyor 1 with value of 0.73 and conveyor 3 with 0.621 . We can conclude that the best solution is conveyor with the highest value, the conveyor 2 .

Conveyor 2 has the speed of the belt $2.4 \mathrm{~m} / \mathrm{s}$, electricity power $30 \mathrm{Kw}$, shipping quantity is 300 $\mathrm{t} / \mathrm{h}$ and 350 eur is cost of $1 \mathrm{~m}$ of the belt.

\section{CONCLUSION}

The subject of the research paper is evaluation of the criteria that are of high importance for conveyor transport. The importance of criteria is evaluated by the AHP method. The technological, economical and external costs has been taken into consideration and five experts evaluated that the biggest importance belong to economic criteria with $59 \%$, then technological criteria with $25 \%$ and with $16 \%$ is external costs. The consistency level of evaluated results is less than 0.1 so, the results can be acceptable by the experts.

Therefore, in the second part of the paper we used a combination of technical and economical subcriteria and by Hurwitz method we selected the best alternative (optimal solution) of the belt conveyor. It was conveyor 2 with the following characteristics (subcriterias): Speed of the belt is $1.5[\mathrm{~m} / \mathrm{s}]$, electricity power is $30[\mathrm{~kW}]$, shipping quantity is $300[\mathrm{t} / \mathrm{h}$ ] and cost of $1 \mathrm{~m}$ of the belt is 350 [Euro].

Methods of multicriteria analysis are gaining in importance and will increasingly be used in the future, not only for conveyor transport but also in other spheres of transport and traffic in order to make the best decisions for achieving maximum efficiency of processes and operations.

\section{REFERENCES}

1. Burdzik R., Ciesla M. and Sładkowski, A. Cargo loading and unloading efficiency analysis in multi- modal transport. Promet - Traffic - Traffico 26(4), 2006, 323-331.

2. Honus S., Bocko P., Bouda T., Ristović I. and Vulić M. The effect of the number of conveyor belt carrying idlers on the failure of an impact place: A failure analysis. Eng. Fail. Anal. 77, 2017, 93-101.

3. Zeman D., Tengler J. and Švadlenka L. The correction of rfid identifiers scanning errors on dynamically moving logistic units. Proceedings of the 14th International Conference Reliability and Statistics in Transportation and Communication 2014, 80-89.

4. Fedorko G., Molnár V., Dovica M., Husáková N., Král' jr. J. and Ferdynus M. The use of industrial metrotomography in the field of maintenance and reliability of rubber-textile conveyor belts in closed continuous transport systems., Eksploat. I Niezawodn. - Maint. Reliab. 18, 2016, 539-543.

5. Kampf R., Průša P. and Savage C. Systematic location of the public logistic centers in Czech Republic. Transport 26(4), 2011, 425-432.

6. Jachowicz T., Sikora J. W. and Dulebova L.: Investigating effects of prodegradant content on selected properties of polymer composite materials. Environmental Engineering and Management Journal 12 (16), 2017, 2879-2886.

7. http://www.hallelujahbelt.com/airport-logistics/

8. Rudawska, A. and Debski H. Experimental and numerical analysis of adhesively bonded aluminium alloy sheets joints. Eksploat. I Niezawodn. Maint. Reliab. 1, 2011, 4-10.

9. Gaudenzi B. and Borghesi A. Managing risks in the supply chain using the AHP method. The International Journal of Logistics Management 17(1), 2006, 114-136.

10. Saaty T.L. Decision Making for Leaders, Lifetime Learning publications. USA, 1982.

11. Warfield J.N. Societal Systems, New York, John Wiley, 1976.

12. Saaty T.L. Axiomatic foundation of the Analytic Hierarchy Process, Management Science 32(7), 1986, 841-855.

13. Alphonce C.B. Application of the Analytic Hierarchy Process in agriculture in developing countries. Agricultural Systems 53(1), 1997, 97-112. 
14. Harker P.T. and Vargas L.G. The theory of ratio scale estimation: Saaty's Analytic Hierarchy Process, Management Science 33(11), 1987, 1383-1403.

15. Saaty, T.L. The Analytic Hierarchy Process, McGraw-Hill, New York, 1980.

16. Molnár V., Fedorko G., Stehlíková B., Tomašková
M. and Hulínová Z. Analysis of asymmetrical effect of tension forces in conveyor belt on the idler roll contact forces in the idler housing. Meas. J. Int. Meas. Confed. 52, 2014, 22-32.

17. Stopka O. and Kampf R. Determining the most suitable layout of space for the loading units' handling in the maritime port. Transport 33(1), 2016, 280-290. 